\title{
MEDICINA, MÉdICOS Y HOSPITALES EN EL CINE DE ALMODÓVAR
}

\section{Medicine, doctors and hospitals in Almodóvar's cinema}

\author{
Eduardo ALONSO FRANCH \\ Universidad de Valladolid (España). \\ Autor para la correspondencia: Eduardo Alonso Franch. \\ Correo electrónico: eduardo.alonso.franch@uva.es
}

Recibido: 19 de mayo de 2021

Aceptado: 1 de junio de 2021

\begin{abstract}
A los sanitarios que trabajan y arriesgan su vida para que salgamos adelante tras la pandemia del coronavirus.
\end{abstract}

\section{Resumen}

El presente artículo supone una contribución al tema del título. En él se hace referencia a la obra de Almodóvar en las últimas cuatro décadas como ejemplo y paradigma del cine español, siendo tal vez su director con más éxito público y de crítica, amén de algunos Oscars para él y sus colaboradores. La medicina juega en su obra un importante papel: médicos y enfermeras, pacientes y transexuales, drogas y drogodependientes, hospitales y ambulatorios aparecen en sus películas. Madrid y Barcelona, así como La Coruña, son las provincias en las que se desarrollan sus narraciones cinematográficas. Las protagonistas femeninas abundan en su filmografía: Marisa Paredes, Penélope Cruz y otras aparecen con frecuencia y de forma repetida. En general, la época suele ser la contemporánea a la de su realización, con alguna excepción referida a 1970. Antonio Banderas es otro de sus actores fetiche, apareciendo en varias ocasiones como médico.

Palabras clave: Pedro Almodóvar; medicina y cine; médicos; hospitales; droga; Madrid.

\section{Abstract}

The present article is a contribution to the subject of the title. In it is referred to the work of Almodóvar on the last four decades as example and paradigm of the spanich cinema, being perhaps his director with more public success \& of criticism, aside of some oscars for it \& his 


\section{MEDICINA, MÉDICOS Y HOSPITALES EN EL CINE DE ALMODÓVAR \\ EDUARDO ALONSO FRANCH}

collaborators. The medecine plays in the work an important role, doctors \& nurses, patients \& transexuals, sexual behaviors, drugs \& drugdependents, hospitals \& ambulatories appears on his films. Madrid and Barcelona, also as La Coruña, are the provinces in what is developed his cinematographic narrations. The female protagonists are frecuents in his films: Marisa Paredes, Penélope Cruz, Cecilia Roth and others appears with frecuency \& in repeted form. generally the age is the contemporanean to his work, with some excepctions referred to 1970. Antonio Banderas is other of his preferred actors, what appears in varied occasions as doctor.

Keywords: Pedro Almodóvar; medicine and cinema; doctors; hospitals; drug; Madrid.

Pedro Almodóvar llega a Madrid en el mítico año 1968 y en 1972 empieza a adentrarse en el mundo cultural alternativo, que vivía los últimos años de la dictadura franquista. Almodóvar se encontraría centrado totalmente en su carrera de director de cine, realizando una película al año. La Movida es el «momento» fundacional de autor de Pedro Almodóvar ${ }^{1}$. La cultura alternativa de los años 70 tuvo en la canción y en el cine dos medios de expresión que permiten percibir de manera muy precisa las modificaciones que se estaban llevando a cabo².

Pedro Almodóvar llegaba a Madrid con el sueño de hacer cine. Por aquellos años Almodóvar comenzaría a viajar entre Madrid y Barcelona. Su apuesta era convertirse en un autor lo suficientemente personal para que sus películas dieran cuenta de su mirada y de su propia vida. Las drogas eran motivo recurrente en sus películas. Sexilia (Cecilia Roth en Laberinto de pasiones) era ninfómana y cantante de rock, además de ser hija de un médico. En 1984, la clase política española se tomó definitivamente la Movida como bandera. Almodóvar tomó experiencias propias del desencanto de la Movida madrileña, y ajenas, que venían de la literatura y el cine. Y lo que había crecido como Movida madrileña ahora se desarrollaba alrededor de Almodóvar. En 1985, Almodóvar era reconocido en su país y comenzaba a serlo fuera de él. Era un director de cine que se atrevía, pero que aún no era por completo aceptado. Le obsesionaba el tema de la muerte. Matador se estrenó sin mucho éxito en el país, pero fue celebrada por críticos como Diego Galán o Vicente Molina Foix. Ahora, los thrillers al estilo de Hitchcock eran su fuente de inspiración. Desde el papel en Matador, el malagueño Antonio Banderas parecía convertirse en el actor fetiche de Almodóvar. El propio Almodóvar reconoció la influencia del director alemán Fassbinder en La ley del deseo. Con Mujeres al borde de un ataque de nervios dio el salto definitivo hacia su proyección internacional. Y fue recomendada por un emocionado Wilder. Billy Wilder es una de las grandes influencias de Almodóvar. En iAtame!, el director apostó por volver una vez más a su pasado. Su nombre entraría de 1990 en adelante a formar parte del olimpo de sus admirados Billy Wilder, Federico Fellini y Douglas Sirk. En 1993, Almodóvar dijo que Kika era su película más personal, más arriesgada. La flor de mi secreto era la segunda etapa de una trilogía sobre la memoria y el pasado, que había comenzado en Tacones lejanos y terminaría en Todo sobre mi madre. La historia de Carne trémula comienza en uno de los momentos más terribles del régimen de Franco. En pleno estado de excepción, en 1970, las calles de Madrid están vacías. Carne trémula es casi una tragedia griega. Abarca un lapso temporal que lleva a los espectadores a 1996, el año de la película. A continuación, quiso hacer una película en la cual se expresarán todas sus obsesiones sobre las mujeres y la maternidad. Todo sobre mi madre trata sobre el dolor a través de una de las actrices que lo acompañaron en los inicios de su carrera, la argentina Cecilia Roth. Una mujer que trabaja como enfermera, y en cuya unidad de cuidados intensivos se realizan dramatizaciones de posibles situaciones a enfrentar con los familiares de los pacientes, experimenta 


\section{MEDICINA, MÉDICOS Y HOSPITALES EN EL CINE DE ALMODÓVAR \\ EDUARDO ALONSO FRANCH}

en carne propia la tragedia de la muerte de su propio hijo. Almodóvar rueda lejos de Madrid. En Todo sobre mi madre, hace un homenaje al sentimiento maternal. En 2003, tiene 53 años. Desde 1979, ha filmado casi una película por año. Rueda también en Valencia. En todos sus personajes hay algo de él. Su última película hasta el 2003 es, una vez más, una mirada sobre su propia formación ${ }^{3}$.

En La ley del deseo, el protagonista (Eusebio Poncela), director y guionista de cine, sufre un accidente de automóvil o intento de suicidio y es internado en un hospital. El médico se compadece de él y advierte a su hermana de que la policía va a registrar su casa. El médico es moreno, serio, de edad mediana, y defiende al paciente ante los policías. Su hermana, Carmen Maura, se cambió de sexo tras una relación incestuosa con su padre. Pablo tiene amnesia y heridas en las piernas. Una joven enfermera está a su lado cuando despierta. Pablo recupera la memoria. Nacho Martínez es el doctor Martín y Germán Cobos hace de cura. El guion y la dirección son de Pedro y la obra es de 1986.

Almodóvar viene de la Mancha, pero es un urbanita cosmopolita y sibarita. Es un hombre débil y desamparado, solitario y trágico. Almodóvar (en Dolor y gloria llamado Salvador) es un hombre en permanente crisis. En Dolor y gloria, los años 80 son la edad heroica de Almodóvar. La fijación de Laberinto de pasiones (1982) por el incesto posee doble filo. De un lado, el gusto por las pasiones extremas; del otro, la subversión / destrucción de la familia. Ya es el único directorestrella del cine hispano. El hogar familiar es parodiado 4 .

En 1984, de nuevo logra la eficacia cómica y el éxito. El Almodóvar exitoso de la segunda mitad de los 80 no es un apocalíptico, sino un integrado. El discurso de Mujeres al borde un ataque de nervios no subvierte el orden social, pero contribuye a demoler la vieja moral sexual. Es un homenaje a aquel Madrid turbulento y contradictorio de los 80. Esta ciudad volverá a ser objeto de alabanza en Carne trémula. En ¡Atame! (1990), Banderas es Almodóvar. 1992 es el momento en que España se convierte en un país moderno. Carne trémula (1997) se realiza ya en la Era Aznar. Historia de amores tormentosos. El protagonista nace en un autobús de línea en pleno estado de excepción de enero de 1970. A la pobreza sociológica de la España de 1970 le sucede la precariedad y marginalidad de los 90. Unas estructuras sociales que, en lo fundamental, no han variado y que se ven amparadas por un esencial continuismo franquista. Se trata posiblemente del mayor discurso apologético del Régimen del 78 trazado en el cine hasta la fecha. Desde entonces hasta hoy, su ingenio irregular pero deslumbrante (que ha conocido recientes cumbres como Hable con ella o Dolor y gloria) se alterna con el oficialismo de gran inversor del Grupo PRISA. Ha representado su época y su país con perspicacia no igualada por cineasta español alguno. Durante decenios, ha sido el único director que ha podido vivir de su trabajo de director.

En iAtame! (1990), el protagonista Antonio Banderas, que sale de un psiquiátrico, rapta a Victoria Abril, ex - toxicómana atendida por una doctora (María Barranco). En el psiquiátrico, Banderas se acostaba con la directora y las enfermeras. En Kika, se trata en clave cómica y desinhibida la violencia doméstica. Hay un voyeur y una psicóloga (Victoria Abril). Se frivolizan también las violaciones. Al final de la obra, que es de 1993, los girasoles recuerdan la película de Vittorio De Sica del mismo título y Doctor Zhivago. Victoria Abril hace de periodista y es una antigua psicóloga. En Mujeres..., las farmacéuticas no pedían recetas. Carne trémula se inicia en Madrid, el mes de enero de 1970, en pleno estado de excepción. La acción continúa un par de décadas más tarde. En la televisión salen hospitales en estado de emergencia (gente que acude a urgencias para eludir trámites). Liberto Rabal está en la cárcel por disparar supuestamente al policía que interpreta Javier Bardem y 


\section{MEDICINA, MÉDICOS Y HOSPITALES EN EL CINE DE ALMODÓVAR \\ EDUARDO ALONSO FRANCH}

su madre (Penélope Cruz) tiene cáncer. Sale de la cárcel cuatro años después. Bardem es tetrapléjico. El director artístico es Antxón Gómez. En agradecimientos se menciona los Ayuntamientos de Madrid y Guadarrama, Colegio Santa María de Aranda de Duero... La obra es de 1997.

Como en Hable con ella o en Volver, también en Los abrazos rotos aparecen hospitales, enfermedades y la amenaza de la muerte con una centralidad dramática inexistente en otros títulos. Entre los varones solo Antonio Banderas tiene una presencia continuada a lo largo de treinta años. Rueda con continuidad en los ochenta y asume papeles muy similares. Pasado el tiempo, vuelve como el perverso médico de La piel que habito. Javier Cámara y Darío Grandinetti coinciden en Hable con ella con dos papeles de hombres sensibles que han de cuidar a mujeres. En Volver, la enferma terminal deja el hospital y regresa al pueblo con el deseo de morir en la cama donde nació. El cuerpo muerto adquiere una trascendencia laica en Todo sobre mi madre, gracias a la donación de órganos. La mayor reflexión sobre el cuerpo se halla en La piel que habito. El cambio de sexo / género forzado de manera violenta es el tema central. Solo el médico de Laberinto de pasiones tiene una aversión apreciada como una patología que se logra superar. Hay que constatar la relevante presencia de las drogas en sus películas. El alcohol figura como estimulante para superar las crisis, al igual que los medicamentos. Las enfermedades se presentan como consecuencia de deficiencias afectivas que llevan a trastornos psíquicos o como un reto para desarrollar afectos, mostrar solidaridad o afianzar las relaciones sentimentales ${ }^{5}$.

Las farmacias son lugares bastante recurrentes. El hospital es un espacio cinematográfico privilegiado, en cuanto que allí siempre tiene lugar un problema o conflicto donde se dirime la vida y la muerte, o cuando menos una enfermedad grave. Las medicinas, en cuanto drogas legales, son utilizadas por las mujeres, que las toman en busca de ayuda para el desamor, el abandono, la soledad, los dolores del alma y la depresión. Abundan los consumidores habituales de medicamentos, en ocasiones junto con el alcohol u otras sustancias estupefacientes. En la mayoría de los casos, se trata de mujeres en crisis. Consciente o no, la ingesta de pastillas puede ocultar cierta voluntad suicida, como en La flor de mi secreto. Además de antidepresivos y drogas que actúan en la psique o en el sistema nervioso central, también aparecen fármacos que actúan sobre la libido. La de los médicos es una de las profesiones más frecuentadas por una filmografía que valora la complicidad con los personajes. Robert Ledgard (La piel que habito) desafía las normas consensuadas por la comunidad científica para emular al doctor Frankenstein. Más humana resulta la psiquiatra de Matador, que interpreta Carmen Maura. Buena parte del metraje de Hable con ella transcurre en un hospital, con personal sanitario de caracterización diversa. En varios films aparecen farmacéuticos. También hay unos estudiantes de Medicina que participan en una manifestación de protesta, en La flor de mi secreto, contra la política sanitaria del Gobierno de Felipe González. La muerte y el sentimiento de dolor por la pérdida, la ausencia o la soledad vertebran toda la historia de Julieta. El material quirúrgico y hospitalario es filmado en planos muy próximos. El suicidio tiene como causa el desamor. Y sucede más en los hombres que en las mujeres. El tema de la muerte resulta central en Volver. El tema del amor seguirá presente en todas sus películas, y la maternidad seguirá siendo abordada tangencialmente, como en Carne trémula.

La película Todo sobre mi madre es muy bien acogida y recibe excelentes críticas: gana el Oscar a la Mejor Película de habla no inglesa y el cine español celebra este tercer galardón. La gran protagonista de Todo sobre mi madre es Cecilia Roth. Penélope Cruz solo había trabajado con Pedro Almodóvar en Carne trémula, en un 
pequeño papel al principio del film. A raíz de Todo sobre mi madre, su salto al cine norteamericano ha sido vertiginoso. Almodóvar es capaz de retratar la marginalidad en toda su crudeza y realidad (palizas, sida, droga, muerte) ${ }^{6}$.

Barcelona se convierte en la ciudad del pasado y en la del futuro, al contrario de Madrid, que ha sido la del dolor. Los edificios modernistas; la fauna urbana, tan variopinta; el mar siempre de fondo, incluso en la muerte de Rosa en el hospital, nos ofrecen una ciudad amable, más acogedora. Manuela se da a conocer en su trabajo, atendiendo a los enfermos. De nuevo su trabajo nos es descrito con mayor minuciosidad, en plena dramatización de una donación de órganos, situación que vivirá ella en breve. Uno de los grandes temas de la película es la maternidad. Manuela es la madre que pierde al hijo y vuelve a recuperarlo en forma de mero hijo adoptivo para reestructurar su vida. Conocemos a Manuela ejerciendo su trabajo, en su entorno laboral, antes de descubrir que tiene un hijo. En Carne trémula, la madre también está sola. Todo sobre mi madre nos muestra la creación de una familia diferente a la convencional. Manuela lleva una vida apacible, con un trabajo que le gusta y un hijo al que adora. En la dramatización que Manuela lleva a cabo sobre la donación de órganos, interpreta a una mujer que ha perdido a su marido en un accidente de tráfico y debe donar su corazón. La ficción nos relata antes que la realidad lo que va a acontecer. La muerte siempre se muestra de antemano en alguna de sus formas. La muerte está omnipresente a lo largo de toda la película. La hermana Rosa es la imagen de la dulzura, de la bondad y la solidaridad. Todo sobre mi madre es una película de mujeres. Rosa está dibujada como una niña inocente, solidaria. La semilla del argumento se recoge en uno de sus filmes anteriores, La flor de mi secreto, en una de cuyas escenas se vivió una situación exacta a la de Manuela. Una enfermera homónima debe realizar una dramatización de donación de órganos.
Penélope Cruz interpreta un papel ya anunciado en Carne trémula. Manuela es una enfermera argentina residente en Madrid y especializada en dramatizaciones de trasplantes, que ve truncada su vida cuando su único hijo muere atropellado. Manuela, desesperada y vacía, decide irse de Madrid a Barcelona, En esta obra, Pedro Lazaga es ayudante de dirección y la dirección artística corre a cargo de Antxón Gómez. La película se rodó en Madrid, La Coruña y Barcelona. En Todo sobre mi madre, se trata de nuevo el tema de los trasplantes, con Cecilia Roth como enfermera del Hospital Ramón y Cajal. Y participa en un seminario sobre el tema de la donación de órganos. Su hijo ha muerto en la $\mathrm{UCl}$ a consecuencia de un atropello. Y la piden que acepte una donación de corazón a otro paciente en espera. A este le implantan en La Coruña el órgano de su hijo. A las tres semanas, ya sale a la calle. Manuela viaja a Barcelona, en donde va a una farmacia con una prostituta, a la que cura de los golpes recibidos en una paliza. Penélope Cruz, monja embarazada, quiere ir al Hospital del Mar para que la revisen. Pero resulta que es seropositiva. Al final, Manuela vuelve a Barcelona para asistir a un congreso sobre el sida. La dirección artística es, también en esta ocasión, tarea de Antxón Gómez. Penélope Cruz es asistente social. El médico le recomienda reposo. Antonia San Juan (Agrado) habla de operaciones de cirugía estética. Penélope Cruz está en el hospital embarazada. Salen Lluís Pascual, director de Bodas de sangre, y Marisa Paredes ensayando.

Madrid enlaza por medio de Almodóvar con ciudades como Barcelona o Toledo. Cuando Pepi y Bom salen del hospital de visitar a Luci, este no es La Paz, que es el que se menciona durante la película, sino el 12 de octubre. En 1988, el hospital cambió su denominación por el actual. Almodóvar retrató un Madrid animadísimo y loco. La ley del deseo se rodó en verano de 1986. El teatro Lara tiene tres siglos de historia. En 1884, cuando el cementerio de La Almudena 


\section{MEDICINA, MÉDICOS Y HOSPITALES EN EL CINE DE ALMODÓVAR \\ EDUARDO ALONSO FRANCH}

estaba en plena construcción, entró ya en uso, al haber una epidemia de cólera en la ciudad. La farmacia Cardona abrió en 1833, por lo que es una de las más antiguas de Madrid. Las instituciones que aparecen en Tacones lejanos (1991) son de un hospital público: el Clínico de San Carlos, fundado en 1787 por Carlos III. Es uno de los hospitales más antiguos de España, estando en sus inicios ubicado en Atocha, en el actual Museo Reina Sofía. El Clínico volvería a aparecer con otro nombre en Los abrazos rotos ${ }^{7}$.

En Todo sobre mi madre, Almodóvar hará que el personaje de Cecilia Roth monte en un AVE para ir a Barcelona. El director, cuando quiere grabar en las afueras de Madrid, decide ir a Parla. Con Todo sobre mi madre, Almodóvar traslada, por primera vez en su filmografía, la mayor parte de la acción a otra ciudad, la capital catalana, donde transcurren tres cuartas partes de la película. Manuela trabaja como coordinadora de trasplantes del hospital Ramón y Cajal. Este centro se inauguró en 1977.

Hable con ella (2002) es una película sobre la soledad y la incomunicación. Almodóvar es el gran cineasta de la capital, como Woody Allen lo es de Nueva York o Fellini de Roma. La clínica El Bosque, que aparece en la película, no es otra que el Hospital Universitario Montepríncipe, en Boadilla del Monte. En Los abrazos rotos (2009), Mateo va a visitar a Diego en el Hospital Quirón de Pozuelo de Alarcón. La cinta, Los abrazos rotos surge en un periodo en el que Pedro sufre severamente de migrañas. En La piel que habito (2011), coloca el centro de la trama en la capital manchega, en la finca El Cigarral. Es la casa de Robert Ledgard (Antonio Banderas), un cirujano plástico que está tratando a Vera (Elena Anaya), ayudado por Marilia (Marisa Paredes). Robert soborna a un enfermero del Hospital Materno Infantil, en cuyo aparcamiento le proporciona placenta para sus experimentos genéticos. Robert da una conferencia en un aula de la Facultad de Medicina de la Universidad Complutense de Madrid. En esta facultad dieron clase Severo Ochoa y Ramón y Cajal, así como Gregorio Marañón. Esta facultad fue la primera que se construyó en la Ciudad Universitaria, pero no se terminó hasta 1949.

En Hable con ella, Leonor Watling es una enferma en coma desde hace cuatro años, que es cuidada por los enfermeros (Javier Cámara y sus compañeras). Javier Cámara (Benigno en la ficción) es un enfermero de tarde y a veces de noche. Geraldine Chaplin va a ver a Alicia y le cuenta sus proyectos en la danza. Catalina (G. Chaplin) era profesora de baile de Alicia. Benigno la siguió y averiguó que el padre de Alicia era psiquiatra. A Alicia le pilla un coche y Benigno la cuida y habla con ella como si estuviera consciente. A Benigno le acusan de haber violado a Alicia y le encarcelan en Segovia. Entre los agradecimientos se menciona al Instituto Cajal del CSIC. La película es de 2002.

En La piel que habito (2011), la acción se inicia en Toledo, en 1980. Banderas da una conferencia médica sobre trasplantes de rostro. Da otra charla en una biblioteca sobre la piel artificial, dirigida a colegas de profesión. Uno de ellos le amenaza por transgredir la bioética. $Y$ otro le pregunta si se dedicará de nuevo a la cirugía. Elena Anaya es su cobaya. Experimenta con ella y la encierra en su mansión. Su hija ha sido internada en un Centro de Investigaciones Neuropsiquiátricas, en donde su médico le pide que no la visite tanto. Ella muere y Banderas amenaza al médico con denunciarle. Al supuesto violador de su hija le hace una vaginoplastia. El director artístico es nuevamente Antxón Gómez.

En Los abrazos rotos, el protagonista es escritor, pero está ciego. Se menciona el caso del hijo de Arthur Miller, que tenía síndrome de Down. Hay un flashback que retrocede hasta 1992. Penélope Cruz es la secretaria de un gran empresario (José Luis Gómez). Su padre tiene cáncer de estómago. Martel le lleva a un hospital privado. El médico dice que no pueden operarle, pero es joven y parece competente. La acción vuelve a 
Madrid en 2008. Volvemos a Madrid en 1994. Se ven carteles de donación de sangre. A Diego le ponen algo en la bebida, se desmaya y entra en coma. Le llevan al Hospital Quirón, pero Diego despierta tras 6 horas. Martel lleva a Penélope Cruz al hospital, después de empujarla y hacer que rodase por las escaleras. Le hacen placas de los huesos y la trata una enfermera. La realizan un TAC y va en silla de ruedas (tiene la pierna escayolada). Homar sufre un accidente y queda ciego. Penélope muere en el choque. El director artístico es de nuevo Antxón Gómez.

En Julieta, la protagonista va a ver a Ava al hospital en donde está ingresada (tiene esclerosis múltiple). Un coche pilla a Julieta, que sufre una herida en un pómulo. Lorenzo (Darío Grandinetti) la lleva al hospital. Julieta está en cama. En Dolor y gloria, Salvador está aquejado de diferentes enfermedades y neurosis que se acrecentarán con la adicción a la heroína ${ }^{8}$. En esta película, el diseño de producción es de Antxón Gómez. Se habla del dolor y las enfermedades, sobre todo de cabeza y espalda, y también de la depresión. Salen una clínica y un médico que atiende a Salvador. Le confiesa que tomó heroína y que ha fumado chinas. Ha tomado ansiolíticos. Se operó la espalda y murió su madre. Tiene, además, un bulto en el esófago que le hace atragantarse. La disfagia produce una osificación y la médica le dice que tiene que operarse. La obra es de 2019. En la ficha técnica, Antxón Gómez figura como director artístico.

Almodóvar se enfrentó al rodaje de Julieta después de un largo parón provocado por una lesión de espalda9 . En Dolor y gloria, la droga conduce a varios viajes somnolientos que van esbozando la biografía de Mallo - Almodóvar desde su presente problemático de ánimo vacilante y cuerpo repleto de goteras. El protagonista nos cuenta con bastante detalle el estado de su organismo. En una de esas consultas, aparece el scanner como nuevo operador connotativo. Y por fin llega la intervención quirúrgica que eliminará los síntomas más preocupantes del paciente cineasta. La anestesia será la llave incitadora en la mente del protagonista. El cine también puede ubicarse dentro de la narración como su motor íntimo y referencial, tal y como hizo Víctor Erice en El espíritu de la colmena (1973) con el Doctor Frankenstein ${ }^{10}$.

En Laberinto de pasiones, el padre de Sexi es un ginecólogo que odia el sexo y por eso ha inventado la inseminación artificial. Retrata a los psiquiatras más bien con crueldad ${ }^{11}$. En 1984, realizó una de sus películas más logradas: ¿Qué he hecho yo para merecer esto? En Todo sobre mi madre, Cecilia Roth interpreta a una enfermera acostumbrada a lidiar con el dolor ajeno que se topará con la muerte accidental de un hijo adolescente ${ }^{12}$. Sus primeras películas trataban temas como el incesto, la homosexualidad, la droga, el sado, el travestismo. La obra de Pedro Almodóvar comporta numerosas referencias cinematográficas. El tema fundamental que encontramos en todas las películas de Pedro Almodóvar es el amor. El psicoanalista de Hable con ella es, al mismo tiempo, el analista de Benigno y el padre de la joven Alicia, de la que Benigno está enamorado. $Y$ todas las películas de Pedro Almodóvar cuentan historias de deseo o de amor frustrado o desdichado (quizás a excepción de iAtame!). En 1999, nos entregó Todo sobre mi madre. Con esta película, Pedro Almodóvar retoma el tema del trasplante de órgano, algo que ya había anunciado en La flor de mi secreto. En las películas de Pedro Almodóvar, el hospital se convierte en un lugar de transformaciones, de implantes. Manuela acepta que trasplanten el corazón de su hijo a un desconocido. La droga es un peligro que acentúa el lado oscuro y excesivo de la vida. En Volver, Agustina, enferma de cáncer, debe ofrecer un testimonio en directo al público para poder operarse en Houston ${ }^{13}$.

Manuela trabaja en un centro médico especializado en la donación de órganos. Tras autorizar la donación del corazón de Esteban, 
Manuela viaja a Barcelona con la intención de encontrar al padre del chico ${ }^{14}$. Sara, monja joven, está embarazada de Lola: Va al Hospital del Mar para que la revisen. A Rosa le hacen una ecografía y le recomiendan reposo y alimentos sin sal. Pide también que le hagan la prueba del SIDA y resulta ser seropositiva. Manuela cree que fue por acostarse con Lola. La culpa está presente en la película e influye en la conducta de las mujeres. Desde la habitación de Rosa se ve el mar, lo mismo que desde el cementerio donde la entierran. Allí aparece Lola, que, como Manuela, es argentina. Dos años después, vuelve con él a Barcelona para asistir a un congreso sobre el SIDA. Lola fue el padre de Esteban (se llama así también) y va a ser el hijo de Rosa, que también se llamará Esteban. Es un cementerio frente al mar (el de Montjuich) entierran a Rosa. Lola va a morirse de inmediato y aparece en el sepelio de Rosa. El niño, cuando vuelve a Barcelona con Manuela, ha negativizado el virus del SIDA. El guion y la dirección de Todo sobre mi madre son de Pedro Almodóvar.

En el cine de Pedro Almodóvar hay más de un personaje que podría inscribirse en los aledaños de la prostitución. Si no se las mata o mueren, casi todas las prostitutas cinematográficas, en algún momento, son maltratadas, apaleadas, violadas o abofeteadas. Otro tema que aparece en épocas recientes es un retrato atroz del mundo de la droga y del trato que se dispensa a las prostitutas, temas que parecen ir juntos. Las relaciones más estables que mantienen las prostitutas son con las amigas (casi siempre compañeras de profesión). Entre nosotros, Almodóvar es el director que más ha presentado a personajes que se mueven por los aledaños de la prostitución. En Todo sobre mi madre (1999), aparece el primer travesti no hormonado que ejerce abiertamente la prostitución ${ }^{15}$.

Hable con ella (2002) fue dirigida y escrito su guion por Pedro Almodóvar. Se rodó, entre otros lugares, en Lucena (Córdoba), Clínica
Montepríncipe (Madrid), Cementerio Sacramental Santa María, Centro Estético Margaret Rose y Thèâtre de la Ville (París). El guion se inspiró en varias historias reales que Almodóvar conoció a través de la prensa durante esos años. Por primera vez en su cine, los protagonistas son dos hombres $^{16}$. Estamos en la clínica privada «El Bosque». En la calle Almagro, en «flashback», Alicia llega al portal de un edificio y Benigno mira cómo pulsa el botón de un timbre del portero automático, junto a una placa brillante. La plaquita metálica tiene grabado: Dr. Roncero. Psiquiatra. En la prisión de Segovia, Benigno, interno, trabaja en la enfermería. La cárcel es nueva y tranquila. Marco descubre sentada en una silla a Alicia, vestida con vaquero y jersey de lana rojo. A su lado hay dos bastones. El guion está fechado en junio de 2001, en Madrid ${ }^{17}$.

Los quirófanos nos remiten a los doctores Jekyll y Caligari, Frankenstein y Moreau, Fu Manchú o Quatermass ${ }^{18}$. A cuatro o cinco kilómetros de Toledo se halla la vasta extensión de El Cigarral, con su casa palacio. El Cigarral fue una clínica de cirugía estética de alto standing. En su interior habita el Doctor Ledgard. El laboratorio de Robert Ledgard cuenta con recipientes donde se cultivan diferentes texturas de piel artificial y con un microscopio. Los cultivos se hacen dentro de una incubadora. "El Cigarral» está protegido por una muralla y una alta puerta con rejas. Buñuel tiene su propia cita, en la primera imagen de la película. Es una vista general de la ciudad de Toledo.

La historia de Dolor y gloria muestra a un hombre a los sesenta años, deprimido por la edad, por una operación de espalda, por la sensación de que no volverá a andar y por su propio aislamiento ${ }^{19}$. Unos enfermeros introducen a Salvador en un quirófano, tumbado en una camilla. El doctor Galindo, de unos 45 años, es el anestesista. Sin pretenderlo, Dolor y gloria es la tercera parte de una trilogía que tardó 32 años en completarse. Las dos primeras partes son La ley del deseo y La mala educación. Las tres películas, 


\section{MEDICINA, MÉDICOS Y HOSPITALES EN EL CINE DE ALMODÓVAR \\ EDUARDO ALONSO FRANCH}

protagonizadas por personajes masculinos que son directores de cine. A lo largo del relato, vemos al veterano director Salvador Mallo en tres épocas de su vida. Con el tiempo, Almodóvar también se fue aislando, sobre todo en el siglo $X X I$. Sus películas se hacen más introspectivas, como resultado de su soledad.

Lluís Homar protagonizó una película de Almodóvar. Su primera colaboración con el director manchego fue en La mala educación. La otra película que haría con Pedro fue Los abrazos rotos. Para Homar, Los abrazos rotos tuvo un rodaje durísimo ${ }^{20}$. Elena Anaya ya era una veterana al lograr el premio de la Academia por mudar de piel. Para llegar a su aspecto, una especie de doctor Frankesntein transformó a su persona de arriba abajo ${ }^{21}$.

\section{Referencias}

1. Zurian Hernández FA. Los inicios de Pedro Almodóvar: en búsqueda de un autor. En Palacio Arranz M, coordinador. El cine y la transición política en España (1975 - 1982). Madrid: Biblioteca Nueva; 2011.

2. Seguin JC. Los inicios de Pedro Almodóvar: en búsqueda de un autor. En Palacio Arranz M, coordinador. El cine y la transición política en España (1975 - 1982). Madrid: Biblioteca Nueva; 2011.

3. Correa Ulloa JD. Pedro Almodóvar. Alguien del montón. Bogotá: Panamericana; 2005.

4. López Sangüesa JL. Almodóvar, años 80: sombra y sueño de un país que huye. Materiales por derribo. Septiembre 2019. (3); 112-70.

5. Sánchez Noriega JL. Universo Almodóvar. Estética de la pasión en un cineasta posmoderno.Madrid: Alianza; 2017.

6. Colmenero Salgado S. Todo sobre mi madre. Pedro Almodóvar. Estudio crítico de. Barcelona: Paidós; 2001.
7. Sánchez Castrejón P. Todo sobre mi Madrid. Un paseo por el Madrid de Almodóvar, desde Pepi, Luci, Bom... hasta Julieta. Madrid: La Librería; 2017.

8. Paredes Badía I. Dolor y gloria: fantasmas del pasado. Dirigido por ...: Revista de Cine. 2019; (497): 16-17.

9. Fernández - Santos E. 'Julieta', el drama más seco de Almodóvar. El País Semanal, 20 de marzo de 2016, (2.060): 30-1.

10. Praga J. Espejos oblicuos: el cine dentro del cine. Materiales por derribo. 2019 (3): 90-102.

11. Vidal N. El cine de Pedro Almodóvar. 3.a ed. Barcelona: Destino; 2000.

12. Polimeri C.: Pedro Almodóvar y el kitsch español. Madrid: Campo de Ideas; 2004.

13. Méjean JM. Pedro Almodóvar. Barcelona: Robinbook; 2007.

14. Huerta Floriano MA: Análisis fílmico del cine español. Sesenta películas para un fin de siglo. Salamanca: Caja Duero; 2006.

15. Gallego J. Putas de película. Cien años de prostitución en el cine. Barcelona: Luces de Gálibo; 2012.

16. Fierro Novo A: Atlas ilustrado del cine español. Madrid: Susaeta; 2011.

17. Almodóvar P. Hable con ella. El guion. Madrid: Ocho y Medio; 2002.

18. Molina Foix V. Prologo: El laboratorio del Doctor Almodóvar. En Almodóvar P., autor. La piel que habito. Barcelona: Anagrama; 2012.

19. Almodóvar P: Dolor y gloria. Barcelona: Random House; 2019.

20. Homar LI: Ahora empieza todo. Barcelona: New Books; 2017.

21. Lahoz J. Mis 100 del cine español. Madrid: Reino de Cordelia; 2019. 